\title{
Is the Canadian health care system ready for donation after cardiac death? A note of caution
}

\section{Christopher James Doig}

"It seems inevitable that the fact that someone else is waiting for this patient's kidney must to some extent influence the decision, since the longer the injured patient is connected to the machines the more his kidneys and other vital organs are likely to deteriorate." - M.F. Woodruff ${ }^{1}$

S ince the seminal report defining criteria for brain death, ${ }^{2}$ organ donations in Canada have been only from individuals who have died after meeting criteria for brain death (donation after brain death or DBD). ${ }^{3}$ However, on June 27,2006 , The Ottawa Hospital announced organ donation from a patient following cardiac arrest, or donation after cardiac death (DCD) ${ }^{4}$ also known as non-heart-beating organ donation (NHBD). In February 2005, the Canadian Council for Donation and Transplantation (CCDT) sponsored a national forum, mainly of health care professionals, that discussed how DCD might proceed in Canada. In a supplement ${ }^{5}$ to this issue of CMAJ is the report from the Forum Recommendations Group (FRG). I was the co-chair of the DCD forum and member of the FRG. At the time of the forum, I was also a member of the CCDT and the chair of the CCDT Donation Committee (although I have since resigned from the CCDT). Although the DCD forum represents good work, and I encourage readers of CMAJ to carefully review the document, at the same time, I have not endorsed the report and cannot support proceeding with DCD based solely on the results of this one forum. DCD may represent an additional source of organs; however, DCD is a major change in end-of-life practice and poses significant ethical problems for end-of-life decisionmaking in intensive care units (ICUs).

DCD may occur in one of the following circumstances: cardiac arrest in a person already "brain-dead," unsuccessful resuscitation of a person in cardiac arrest and cardiac arrest following withdrawal of treatment in the ICU. DCD from the last category is known as "controlled" DCD, because methods to preserve organ viability are initiated before the donor's death, and timing the death (withdrawal of lifesustaining treatment) can be controlled around organizational factors such as operating room and surgical team availability. Today, in the United States, organs recovered from controlled DCD donors have virtually supplanted the other categories of DCD. ${ }^{6}$

DCD is not new: in the infancy of organ transplantation, "controlled" DCD donors were the primary source of organs for transplant. This was not because of certainty concerning the propriety of using organs from these donors. DCD was abandoned in North America in part following the publication of brain death criteria authored by the ad hoc committee of department heads from the Harvard Medical School. ${ }^{2}$ They wrote "Our primary purpose is to define irreversible coma as a new criterion for death. There are two reasons why there is a need for a definition: (I) Improvements in resuscitative and supportive measures have led to increased efforts to save those who are desperately injured. Sometimes these efforts have only partial success so that the result is an individual whose heart continues to beat but whose brain is irreversibly damaged. The burden is great on patients who suffer permanent loss of intellect, on their families, on the hospitals, and to those in need of hospital beds already occupied by those comatose patients. (2) Obsolete criteria for the definition of death can lead to controversy in obtaining organs for transplantation." Both of these reasons remain relevant today. The crux of this issue is that for patients with all types of severe brain injury (these are the patients primarily considered for DCD) treatments have advanced considerably, making it extremely difficult to predict not only survival but also longterm recovery. With DCD a patient must be considered a potential donor before their death. Therefore, there is an inherent conflict of interest for physicians caring for these and other individuals in the ICU who might also be candidates for controlled DCD: attempts to preserve the life of a patient might limit or preclude these same individuals from being organ donors. This issue is no different from that stated by M.J. Woodruff that introduces this commentary. The development of brain death criteria and DBD resolved this conflict, because the physician's duty to attempt to preserve the patient's life clearly ended with the patient's death. Only after death would the physician then consider the patient a potential donor and approach the family about organ donation.

End-of-life practices including predicting outcome would not be an issue if there was clear consensus and practice. However, Canadian research has demonstrated considerable variability in determining from whom and how to withdraw life-sustaining treatments in the ICU. Cook et $\mathrm{al}^{7}$ surveyed more than 1600 Canadian ICU health care providers with I2 standardized and "usual" ICU scenarios to ascertain treatment recommendations from 5 potential options, ranging from continuing full management, to limiting some treatment interventions (for example, not instituting dialysis), to withdrawal of all active treatment. In only I of the I2 scenarios was the same option chosen by more than $50 \%$ of respondents. In 8 of $\mathrm{I} 2$ scenarios, opposite extremes of care were chosen by more than $10 \%$. Factors associated with treatment decisions included years since graduation, city and province of work, number of beds within the ICU where they worked, and self-perceived likelihood of limiting treatment relative to colleagues. More recent work from Cook and other collaborators $^{8}$ examined withdrawal of mechanical ventilation in anticipation of death in I66 of 85I ICU patients. Of the I66, only I45 actually died in the ICU, and of the remaining 2I, 6 (3.6\% 
of the I66) were ultimately discharged home, despite the withdrawal of treatment because death was anticipated. When there is such variability in end-of-life ICU practice, the possibility of conflicted decision-making in a controlled DCD program is more than a theoretical possibility. Other Canadian research has demonstrated that families and patients consider trust in their physicians (and other health care providers) as paramount in making end-of-life decisions. ${ }^{9}$

Baylis ${ }^{10}$ has stated concerning another controversial ethical topic that neither the Canadian health care system nor a broad social consensus has conferred upon physicians [or other health care professionals] the authority to make unilateral decisions. In my opinion, a forum focusing exclusively on how end-of-life decisions are made that involves a much broader representation of health care professionals, experts in health law and ethics, and the general public, including groups with special interest such as those that represent people with brain injuries, is required before proceeding with DCD. To proceed before such a specific forum is premature and could rightly cast doubt on the intentions and practices of health care professionals particularly in the ICU, and on organ donation practices as a whole.

This article has been peer reviewed.

Christopher James Doig is with the Departments of Critical Care Medicine and Community Health Sciences, Office of Medical Bioethics, University of Calgary, Calgary, Alta.
Competing interests: None declared.

\section{REFERENCES}

I. Woodruff MF. Ethical problems in organ transplantation. BMJ I964;5396:1457-60.

2. A definition of irreversible coma. Report of the Ad Hoc Committee of the Har vard Medical School to Examine the Definition of Brain Death. JAMA i968;205: $337-40$

3. Barnieh L, Baxter D, Boiteau P, et al. Benchmarking performance in organ donation programs: dependence on demographics and mortalilty rates. Can J Anaesth 2006;53:727-3I.

4. New era for organ donation in Canada: donation after cardiac death performed successfully in Ottawa [press release]. Available: www.giftoflife.on.ca/assets /pdfs/NeweraJuneo6.pdf (accessed 2006 Sept. I2).

5. Shemie SD, Baker AJ, Knoll G, et al. Donation after cardiocirculatory death in Canada. CMAJ 2006;175(8 suppl):Si-24.

6. Bernat JL, D'Alessandro AM, Port FK, et al. Report of a national conference on donation after cardiac death. Am J Transplant 2006;6:28I-9I.

7. Cook DJ, Guyatt GH, Jaeschke R, et al. Determinants in Canadian health care workers of the decision to withdraw life support from the critically ill. Canadian Critical Care Trials Group. JAMA I995;273:703-8.

8. Cook DJ, Rocker G, Marshall J, et al. Withdrawal of mechanical ventilation in an ticipation of death in the intensive care unit. NEngl J Med 2003;349:I123-32.

9. Heyland DK, Dodek P, Rocker G, et al. What matters most in end-of-life care: perceptions of seriously ill patients and their family members. CMAJ 2006;174: 627-33.

Io. Baylis F. Expert testimony by persons trained in ethical reasoning: the case of Andrew Sawatzky. J Law Med Ethics 2000;28:224-31.

Correspondence to: Dr. Christopher James Doig, Critical Care Medicine, Community Health Sciences, Office of Medical Bioethics, University of Calgary, EG $23 G-140329$ th Street $N W$, Calgary AB T2N 2T9; fax 403 283-9994; cdoig@ucalgary.ca

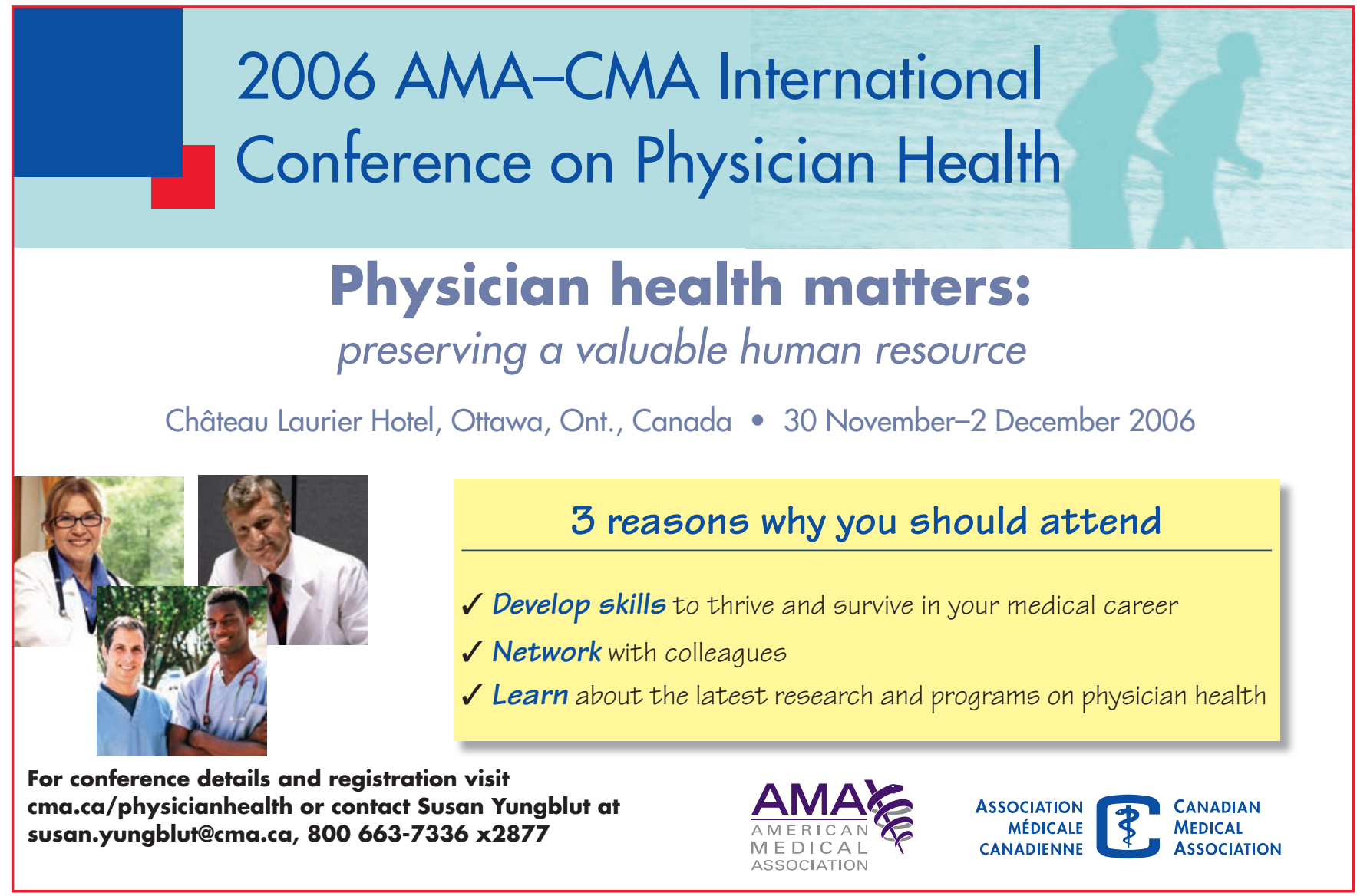

